\title{
Forest leaf area index determination: A multiyear satellite- independent method based on within-stand normalized difference vegetation index spatial variability
}

\author{
G. le Maire, ${ }^{1,2}$ C. François, ${ }^{1}$ K. Soudani, ${ }^{1}$ H. Davi, ${ }^{1,3}$ V. Le Dantec, ${ }^{4}$ B. Saugier, ${ }^{1}$ \\ and E. Dufrêne ${ }^{1}$
}

[1] The Leaf Area Index (LAI) and its spatial distribution are key features to describe the forest ecophysiological processes. A stable and reproducible relationship is obtained between the LAI and the standard deviation $\sigma_{\mathrm{NDVI}}$ of the pixel-based satellite-derived normalized difference vegetation indices (NDVI) of forest stands. In situ measurements of LAI have been performed with the LAI-2000 Plant Canopy Analyser over 8 years in the managed Fontainebleau forest (France) on about 31 stands each year, including oak, beech, and mixed oak-beech stands. Simultaneous satellite images have been acquired, atmospherically and geometrically corrected, and included into a geographic information system to get the mean NDVI and the $\sigma_{\mathrm{NDVI}}$ for each stand. A total of six different satellites with a 20- to 30-m spatial resolution have been considered over the eight studied years: SPOT1, SPOT2, SPOT4, LANDSAT ETM+, IKONOS, and HYPERION. The mean LAI of a stand is linked to the $\sigma_{\mathrm{NDVI}}$ with a unique relationship that appears to be mostly year- and satellite-independent, because the $\sigma_{\mathrm{NDVI}}$ is nearly insensitive to additive or proportional shifts on NDVI. The theoretical bases of the $\sigma_{\mathrm{NDVI}}$-LAI relationship are investigated. The results show the combined importance of the shape of the within-stand LAI distribution (following a Weibull probability density function) and the shape of the within-stand LAI-NDVI curves (showing a saturation). The root mean square error of the predicted LAI over the 259 samples is $1.14 \mathrm{~m}^{2} / \mathrm{m}^{2}$ when all years and satellites are considered, using the following equation: $\mathrm{LAI}=-2.45 \ln \left(\sigma_{\mathrm{NDVI}}\right)-5.58$ $\left(r^{2}=0.63\right)$.

Citation: le Maire, G., C. François, K. Soudani, H. Davi, V. Le Dantec, B. Saugier, and E. Dufrêne (2006), Forest leaf area index determination: A multiyear satellite-independent method based on within-stand normalized difference vegetation index spatial variability, J. Geophys. Res., 111, G02027, doi:10.1029/2005JG000122.

\section{Introduction}

[2] Leaf area index (LAI), defined as the surface of tree leaves per ground surface area, is a key parameter implied in a variety of forest ecosystem processes, including light and rain interception, transpiration, photosynthesis, and soil heterotrophic respiration (through litter fall). Its precise estimation is crucial for ecosystem modeling at the landscape or regional scale with process-based models that quantify carbon, water, and energy fluxes.

[3] Local estimations of LAI are often performed through optical (LI-COR LAI-2000, hemispherical photographs),

\footnotetext{
${ }^{1}$ Laboratoire Ecologie, Systématique et Evolution (ESE), CNRS/ Université Paris Sud, Orsay, France.

${ }^{2}$ Now at Laboratoire des Sciences du Climat et de l'Environnement (LSCE), Unité Mixte CNRS-CEA, Gif-sur-Yvette, France.

${ }^{3}$ Now at Unité de Recherches Forestières Méditerranéennes (UR 629), Institut National de la Recherche Agronomique, Avignon, France.

${ }^{4}$ Centre d'Etudes Spatiales de la Biosphère (CESBIO), Toulouse, France.
}

direct and semidirect methods (litter collection and allometric methods). Routine in situ measurements of LAI, however, are time-consuming and even unfeasible for large-scale studies. For that reason, numerous works attempt to characterize LAI through remotely sensed data [Rouse et al., 1973; Curran, 1980; Justice et al., 1998; North, 2002]. The data acquired by remote sensing over vegetation areas give the reflectance in different spectral bands and with a given spatial resolution. LAI is classically derived from a combination of well-chosen spectral band reflectances [Goel and Qin, 1994; Turner et al., 1999; Walthall et al., 2004].

[4] Particularly, empirical relationships between LAI and Spectral Vegetation Indices (SVI) such as the Normalized Difference Vegetation Indices (NDVI) are widely used in the remote sensing community [Chen et al., 1997; Turner et al., 1999]. However, these relationships between LAI and remote-sensing vegetation indices, especially the NDVI, have several recognized drawbacks [Qi et al., 2000]: (1) saturation of NDVI for LAI greater than $3.5 \mathrm{~m}^{2} / \mathrm{m}^{2}$ [Lüdeke et al., 1991; Fassnacht et al., 1997; Birky, 2001; Anderson et al., 2004; Wang et al., 2005], (2) the fact that a relationship established between the LAI and the vegetation 
index for a particular satellite sensor is generally not applicable to other sensors [Teillet et al., 1997; Wang et al., 2005; Soudani et al., 2006], (3) the previous point is also true for relationships between years for the same sensor [Wang et al., 2005], and (4) the fact that this relationship appears to be greatly species- and site-dependent [Qi et al., 2000; Colombo et al., 2003].

[5] The methods for analyzing remotely sensed images are usually pixel based; that is, the LAI is calculated for each pixel independently of the surrounding ones and then averaged over the stands if necessary. The use of satellite data is particularly interesting in intensively managed ecosystems, where stand polygons may be referenced in Geographic Information System (GIS) software for management practical reasons. These polygons, generally obtained by interpretation of aerial photographs, contain uniform attributes of interest to the manager. In a managed forest, the attributes that differentiate one stand from another (i.e., the criterion for the polygon mapping) may be species, age for even-aged stands, and tree density. The polygon mapping can be used to calculate a statistic for each polygon using the within-polygon pixels of the remotely sensed image: The statistic can be, for instance, the mean NDVI of the stand. For a selected set of stands, these stand-scale statistics can then be linked through empirical equations to stand measured characteristics, as the stand mean LAI. These empirical equations can finally be applied to other polygons. This polygon approach is of great interest for modeling purposes where such polygons may be used as simulation units in regional studies with process-based ecosystem models [le Maire et al., 2005]. The polygonbased approach for analyzing remotely sensed data was also shown to be more accurate than the pixel-based approach by reducing local data noise and allowing the exclusion of pixels on the boundaries of two contrasting stands [Wulder, 1998; Wicks et al., 2002].

[6] In the present study a stable and reproducible relationship is obtained between the LAI and the standard deviation of the NDVI of that stand. Standard deviation or variance measurements of reflectances are usually used to characterize the texture of an image, generally through a moving window [Lillesand and Kiefer, 2000]. The variation in texture, characterizing the relationship between neighboring pixels, has been related to spatial variation in vegetation distribution and mostly used for forest stand classification [St. Onge and Cavayas, 1995; Lark, 1996; Ryherd and Woodcock, 1996; Coburn and Roberts, 2004].

[7] Relatively few studies have focused on the use of texture properties to estimate the LAI. Wulder et al. [1996, 1998] show that the classical LAI-NDVI relationship on deciduous forests is improved if the texture (based on GreyLevel Co-occurrence Matrix, GLCM) is included as a second independent variable, compared to NDVI alone. Their interpretation is that the empirical relationship between LAI, NDVI, and texture is possible because of complementary information content: the texture variables are sensitive to stand structural characteristics while NDVI is sensitive to the vegetation content.

[8] Instead of considering separately NDVI and texture, Davi et al. [2006], using the variance of the NDVI as a texture measurement, have shown with SPOT images the existence of a linear relationship between LAI of forest stands and the logarithm of the variance of the NDVI. As noted by Coburn and Roberts [2004], the use of variance as a measure of texture instead of GLCM has not been extensively used yet in the remote sensing community. The relationship obtained by Davi et al. [2006] gave an RMSE of $1.13 \mathrm{~m}^{2} / \mathrm{m}^{2}$ on the estimated LAI. The present study shows the existence of a single largely applicable relationship between the mean LAI of a stand (LAI, $\mathrm{m}^{2} / \mathrm{m}^{2}$ ) and the standard deviation of the within-stand NDVI pixels $\left(\sigma_{\mathrm{NDVI}}\right)$, with different satellites and years. The experimental data set consists of 8 years (between 1994 and 2004) of measurements on deciduous stands and six different satellites (SPOT1, SPOT2, SPOT4, LANDSAT ETM+, IKONOS, and HYPERION), which allow us to assess the generality of the relationship between $\overline{\mathrm{LAI}}$ and $\sigma_{\mathrm{NDVI}}$.

[9] The objectives of this article are (1) to investigate the theoretical bases of the $\overline{\mathrm{LAI}}-\sigma_{\mathrm{NDVI}}$ relationship using Weibull modeled LAI distribution fitted on real LAI distributions coupled with LAI - NDVI within-stand relationships; (2) to compare the strength and accuracy of the classical $\overline{\mathrm{LAI}}$ versus mean stand NDVI ( $\overline{\mathrm{NDVI}})$ approach to the new $\overline{\mathrm{LAI}}-\sigma_{\mathrm{NDVI}}$ approach on 8 years of data with six satellites (259 stands); (3) to test the sensitivity of the standscale $\overline{\mathrm{LAI}}-\overline{\mathrm{NDVI}}$ and $\overline{\mathrm{LAI}}-\sigma_{\mathrm{NDVI}}$ relationships to variation of the pixel-based NDVI over the image (which may come from year to year atmospheric variations, changes in soil surface properties, and satellite sensor variations such as drifts or inappropriate calibrations); (4) to test the sensitivity of the $\overline{\mathrm{LAI}}-\sigma_{\mathrm{NDVI}}$ relationship to variations in the satellite image spatial resolution; and (5) to show on a given year and for all deciduous stands of a managed forest that the $\sigma_{\text {NDVI }}$ is more reliable, i.e., constant, than the $\overline{\text { NDVI }}$ between different satellite images.

\section{Material and Methods}

\subsection{Study Site}

[10] The Fontainebleau forest, located in the southeast of Paris $\left(48^{\circ} 25^{\prime} \mathrm{N}, 2^{\circ} 40^{\prime} \mathrm{E}\right.$, mean altitude $\left.120 \mathrm{~m}\right)$ is a large forest extending over 17,000 ha in a region characterized by a temperate climate, with a mean annual temperature of $10.6^{\circ} \mathrm{C}$ and mean precipitation of $750 \mathrm{~mm}$ fairly well distributed throughout the year. This forest is actively managed by the French National Forest Office ("Office National des Forêts", ONF), and divided into 2992 management units localized on a GIS database (with the software ArcGIS 8.1, Environmental Systems Research Institute Inc., Redlands, California). These management units, called "stands" in this study, are even-aged and homogeneous in species, stand structure, and tree density. The Fontainebleau forest is representative of an even-aged high forest, with the successive stage development describing the stand structure including: seedlings, thickets, sapling stands, pole stands, mature forest, and seed tree stands. These successive development stages are the result of regular forestry practices that strongly modify the stand structure and species composition of the forest.

[11] Thirty-one experimental stands were selected in flat areas. They include the two main deciduous species of the Fontainebleau forest: oak (Quercus robur L./Quercus petraea (Matt.) Liebl., 14 stands) and beech (Fagus sylvatica L., 13 stands), and mixed oak-beech (dominated 
Table 1. Details of the in Situ Measurements: Number of Stands for Each Species and Period of LAI Measurement ${ }^{\mathrm{a}}$

\begin{tabular}{|c|c|c|c|c|c|c|}
\hline \multirow[b]{2}{*}{ Satellite } & \multirow[b]{2}{*}{ Acquisition Date } & \multicolumn{4}{|c|}{$\mathrm{Nb}$ of Measured Stands } & \multirow[b]{2}{*}{ LAI Measurement Date } \\
\hline & & Total & Oak & Beech & Oak-Beech & \\
\hline SPOT2 - HRV2 & 10 July 1994 & 22 & 11 & 9 & 2 & 27-29 June 1994 \\
\hline SPOT2 - HRV2 & 10 July 1995 & 30 & 14 & 12 & 4 & 26-30 June 1995 \\
\hline SPOT2 - HRV1 & 17 July 1996 & 31 & 14 & 13 & 4 & 27 June to 17 July 1996 \\
\hline SPOT1 - HRV1 & 13 Aug 1997 & 29 & 13 & 12 & 4 & 8-22 July 1997 \\
\hline SPOT1 - HRV1 & 06 Aug 1998 & 29 & 12 & 13 & 4 & 23 June to 06 August 1998 \\
\hline SPOT4 - HRVIR & 21 July 2000 & 23 & 7 & 12 & 4 & 21 July to 10 August 2000 \\
\hline Landsat - ETM+ & 24 Aug 2000 & 21 & 6 & 11 & 4 & 21 July to 10 August 2000 \\
\hline IKONOS & 16 Aug 2000 & 16 & 6 & 7 & 3 & 21 July to 10 August 2000 \\
\hline SPOT2 - HRV1 & 20 July 2002 & 25 & 11 & 10 & 4 & 24-26 June 2002 \\
\hline Landsat - ETM+ & 29 July 2002 & 25 & 11 & 10 & 4 & 24-26 June 2002 \\
\hline EO1-HYPERION & 04 Sep 2004 & 8 & 5 & 1 & 2 & $6-10$ Sept 2004 \\
\hline
\end{tabular}

${ }^{\text {a }}$ The dates of the corresponding satellite images are also given.

by oak, 4 stands). These stands are representative of the different stage developments and stand structure of deciduous stands found in the Fontainebleau forest. A detailed description of the Fontainebleau experimental stands in terms of stand structure, maximum height, diameter at breast height, density, age, and basal area is given by Le Dantec et al. [2000].

[12] In this paper, these stands are defined as "homogeneous" since they are even-aged, with a given species composition, and without localized broads gaps or tree clumps. These stands, however, are not homogeneous regarding the LAI, which is spatially variable within the stands.

\subsection{Ground-Based LAI Data Collection}

[13] The Plant Canopy Analyser (PCA) LAI-2000 (LI-COR Inc., Nebraska) was used for ground LAI measurements. A detailed description of this instrument is given by Cutini et al. [1998]. Calculations were carried out using three rings, which give an approximate value for the integration surface covered by the LAI-2000 of $300 \mathrm{~m}^{2}$, depending on tree height. A detailed description and analysis of the LAI measurement method is given by Dufrêne and Bréda [1995], Le Dantec et al. [2000] and Soudani et al. [2006]. LAI measurements were performed on the 31 experimental stands each year from year 1994 to year 2004 in summer when LAI has reached a maximum (Table 1). Note that LAI is not measured every year for all stands; over the 8 years, a total of 197 forest-stand samples were available. For each stand, and according to its size, 40 to 150 LAI-2000 measurements were taken each year of measurements at intervals of $8 \pm 2 \mathrm{~m}$ on several transects. The sampling covers between $5 \%$ and $68 \%$ of the stand area, depending on stand area and on tree height. LAI is calculated for each local measurement with the equations given by Miller [1967] and its distribution inside the stand is obtained. The sampling density allows us to get the mean LAI of the stand ( $\overline{\mathrm{LAI}})$ as well as the LAI distribution inside the stand and its standard deviation $\sigma_{\text {LAI }}$.

\subsection{Satellite Images Acquisition and Processing}

[14] Eleven images were acquired with six different sensors between 1994 and 2004 during the period of maximum LAI. Spatial resolution in multispectral mode and bandwidth of these sensors are given in Table 2, with the date and acquisition geometry. In order to compute surface reflectance, images were geometrically and atmo- spherically corrected. Images were first rectified and georeferenced using ground control points and integrated in the GIS database of Fontainebleau forest. Digital counts (gray tone) were converted to at-satellite (top of atmosphere) radiance using the gains and the offsets contained in the image headers and then calibrated to scaled surface reflectance after atmospheric corrections using a Dark Object Subtraction (DOS) approach [Song et al., 2001]. The methodology is fully described by Soudani et al. [2006] where the same year 2000 images (IKONOS, ETM+, and SPOT) were corrected. The same methodology is used for the other SPOT and ETM+ images. The IKONOS image has a 4-m spatial resolution that has been resampled to get the same resolution as other sensors $(20 \mathrm{~m})$. HYPERION is a hyperspectral sensor that acquires data in about 200 narrow bands between 400 and $2500 \mathrm{~nm}$. We averaged the HYPERION spectral bands in the red and in the NIR domain to get broad bands similar to the ETM + sensor. This step is followed by the DOS atmospheric correction method. The normalized difference vegetation index (NDVI) is then calculated for each pixel of each image with the reflectance in the near infrared $\left(R_{N I R}\right)$ and in the red band $\left(R_{R E D}\right)$ : $\mathrm{NDVI}=\left(\mathrm{R}_{\mathrm{NIR}}-\mathrm{R}_{\mathrm{RED}}\right) /\left(\mathrm{R}_{\mathrm{NIR}}+\mathrm{R}_{\mathrm{RED}}\right)$.

\subsection{Data Extraction and GIS Computations}

[15] The 31 experimental stands are localized with aerial photographs and their polygons are drawn on the GIS database. The 11 satellite NDVI images are included in this GIS database. For each experimental stand, the pixel-based NDVI values were extracted, discarding the pixels on the edge of the stand: A buffer of $60 \mathrm{~m}$ was used, which corresponds to a width of at least 2 pixels. This wide buffer excludes the pixels that are on the boundaries of two stands, and limits small residual errors on images due to geometric rectification and georeferencing. The choice of the buffer width is discussed further. The number of pixels extracted per stand varies from 45 to 125 , depending on stand size and on satellite resolution, with an average of 75 pixels. From these values, mean NDVI ( $\overline{\mathrm{NDVI}})$ and standard deviation of the NDVI $\left(\sigma_{\mathrm{NDVI}}\right)$ were calculated for each stand and for each satellite image. A total of 259 samples were extracted over the eight different years and six satellites (11 images).

[16] The same methodology of NDVI extraction is applied on year 2000 to the entire Fontainebleau forest 
Table 2. Characteristics of the Satellite Images Used in the Paper: Date and Time of Acquisition, Pixel Size, View and Sun Geometry ( $\theta$ is the Zenithal Angle), and Spectral Bands

\begin{tabular}{|c|c|c|c|c|c|c|c|}
\hline$\underline{\text { Satellite - Instrument }}$ & Acquisition Date & Spatial Resolution & Time, UT & $\theta_{\text {sun }}$, deg & $\theta_{\text {view }}$, deg & Red Band, nm & NIR Band, nm \\
\hline SPOT2 - HRV2 & 10 July 1994 & $20 \mathrm{~m}$ & 1100 & 27.4 & 4.0 & $610-680$ & $790-890$ \\
\hline SPOT2 - HRV2 & 10 July 1995 & $20 \mathrm{~m}$ & 1041 & 29.7 & 21.7 & $610-680$ & $790-890$ \\
\hline SPOT2 - HRV1 & 17 July 1996 & $20 \mathrm{~m}$ & 1107 & 28.7 & 14.8 & $610-680$ & $790-890$ \\
\hline SPOT1- HRV1 & 13 Aug 1997 & $20 \mathrm{~m}$ & 1053 & 35.5 & 3.9 & $610-680$ & $790-890$ \\
\hline SPOT1 - HRV1 & 06 Aug 1998 & $20 \mathrm{~m}$ & 1116 & 32.3 & 23.7 & $610-680$ & $790-890$ \\
\hline SPOT4 - HRVIR & 21 July 2000 & $20 \mathrm{~m}$ & 1109 & 29.4 & 12.0 & $610-680$ & $780-890$ \\
\hline Landsat - ETM+ & 24 Aug 2000 & $30 \mathrm{~m}$ & 1031 & 41.4 & 0.0 & $630-690$ & $760-900$ \\
\hline IKONOS & 16 Aug 2000 & $4 \mathrm{~m} \rightarrow 20 \mathrm{~m}^{\mathrm{a}}$ & 1052 & 36.9 & 23.6 & $632-698$ & $757-853$ \\
\hline SPOT2 - HRV1 & 20 Jul 2002 & $20 \mathrm{~m}$ & 1117 & 28.5 & 23.7 & $610-680$ & $790-890$ \\
\hline Landsat - ETM+ & 29 Jul 2002 & $30 \mathrm{~m}$ & 1029 & 34.8 & 0.0 & $630-690$ & $760-900$ \\
\hline EO1 - HYPERION & 04 Sept 2004 & $30 \mathrm{~m}$ & 1030 & 46.4 & 4.0 & $630-690^{\mathrm{b}}$ & $760-900^{\mathrm{b}}$ \\
\hline
\end{tabular}

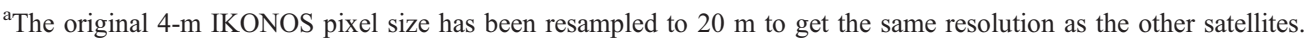

${ }^{\mathrm{b}}$ Several hyperspectral bands have been averaged to obtain the indicated bandwidth.

(SPOT4, LANDSAT ETM+, and IKONOS images), using the GIS database created by the French National Forest Office (ONF) that contains the polygon delineation of the 2992 management units. The $\overline{\mathrm{NDVI}}$ and $\sigma_{\mathrm{NDVI}}$ are calculated for every stand, respecting a buffer of $60 \mathrm{~m}$ as explained for the experimental stands. Only the oak and beech stands greater than 2 ha after buffer elimination are kept for the analysis. The 2-ha threshold corresponds to 22 pixels of $30 \times$ $30 \mathrm{~m}$ and is considered statistically sufficient for a standard deviation calculation. Stands with clouds were visually eliminated. The $\overline{\mathrm{NDVI}}$ and $\sigma_{\mathrm{NDVI}}$ were finally calculated on the three satellite images of the year 2000 on 293 stands. Because the IKONOS image does not cover the whole forest, only 144 stands are used with this image.

\section{Theoretical Basis of the $\overline{\mathbf{L A I}}-\sigma_{\mathrm{NDVI}}$ Relationship}

[17] The theoretical basis of the observed $\overline{\mathrm{LAI}}-\sigma_{\mathrm{NDVI}}$ relationship [Davi et al., 2006] is studied here using a within-stand LAI distribution modeled with a Weibull Probability Density Function (PDF), previously calibrated on the experimental stands of the Fontainebleau forest (see Appendix A). This modeled LAI distribution is then transformed into a NDVI distribution using a within-stand LAI-NDVI relationship (see Appendix A). Then the $\overline{\mathrm{LAI}}-\sigma_{\mathrm{NDVI}}$ relationship is established and analyzed. This modeling approach allows us to study various factors that may affect the shape of the $\overline{\mathrm{LAI}}-\sigma_{\mathrm{NDVI}}$ relationship: (1) the shape of the within-stand LAI-NDVI relationship and (2) the shape of the distribution of the LAI within the stand. The aim of this chapter is to study the effect of these factors, and their relative importance on the final result.

[18] To study the first factor, four different arbitrarily chosen within-stand LAI-NDVI relationships were created; they go from a highly saturated one to a linear one (Figure 1). To study the second factor, the Weibull distribution of the LAI was changed into a Gaussian one with the mean equal to $\overline{\mathrm{LAI}}$ and the standard deviation parameter fixed to a constant value $\left(\sigma=1.2 \mathrm{~m}^{2} / \mathrm{m}^{2}\right.$, computed as the square root of the average LAI variances over the 197 forest-stand samples). In the case of the Gaussian distribution, the shape of the distribution is therefore identical whatever the $\overline{\mathrm{LAI}}$ contrary to the case of the Weibull distribution where the shape depends on $\overline{\mathrm{LAI}}$ (Appendix A).

[19] The two LAI distributions (Weibull and Gaussian) were tested together with the four LAI-NDVI relationships, leading to eight different cases. Figure 2 represents $\sigma_{\text {NDVI }}$ versus $\overline{\mathrm{LAI}}$ for these eight cases (note that case 2, medium saturation and Weibull distribution, is close to the real case).

\subsection{Test of the First Factor: Shape of the Within-Stand LAI-NDVI Curve}

[20] In the case of the Weibull LAI distribution model, when the LAI-NDVI relationship shows more saturation, the range of variation of the $\sigma_{\mathrm{NDVI}}$ increases. The maximum of the $\overline{\mathrm{LAI}}-\sigma_{\mathrm{NDVI}}$ curves shifts leftward, so that for the medium and high saturation cases the $\sigma_{\mathrm{NDVI}}$ monotonically decreases for $\overline{\mathrm{LAI}}$ greater than $0.5 \mathrm{~m}^{2} / \mathrm{m}^{2}$. For the most saturated LAI-NDVI relationship, however, (Figure 2a, case 1) the standard deviation becomes nearly constant for $\overline{\mathrm{LAI}}$ greater than 3 or $4 \mathrm{~m}^{2} / \mathrm{m}^{2}$ (this zone corresponds to the saturation plateau of the LAI-NDVI curve). For the medium saturation case, both the amplitude and the position of the maximum $\sigma_{\mathrm{NDVI}}$ allow the prediction of the $\overline{\mathrm{LAI}}$ between approximately 0.5 and $6 \mathrm{~m}^{2} / \mathrm{m}^{2}$. These results show that, considering a within-stand LAI Weibull distribution, a part of the link between the $\overline{\mathrm{LAI}}$ and the $\sigma_{\text {NDVI }}$ comes from the saturation of the LAI-NDVI curve, but that a too high saturation erases this signal for $\overline{\mathrm{LAI}}$ greater than 5 or $6 \mathrm{~m}^{2} / \mathrm{m}^{2}$.

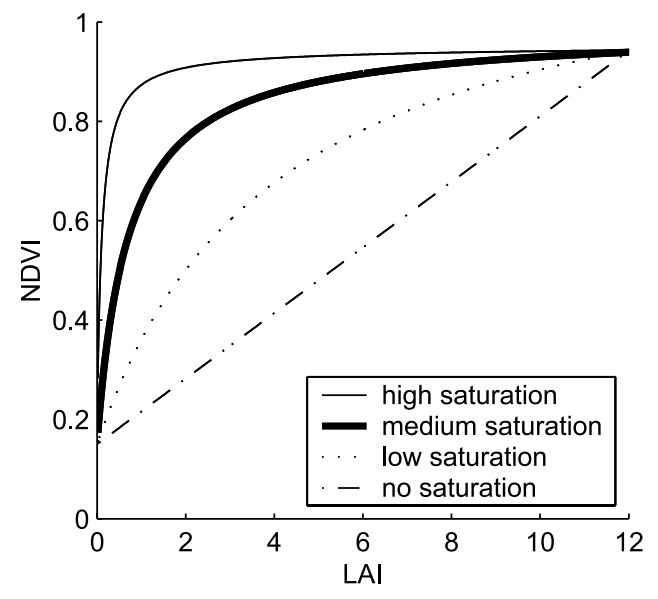

Figure 1. Four LAI-NDVI relationships created to test the theoretical basis of the $\overline{\mathrm{LAI}}-\sigma_{\mathrm{NDVI}}$ relationship using modeling. They go from a highly saturated one to a linear one. 
(a) With LAI Weibull distribution

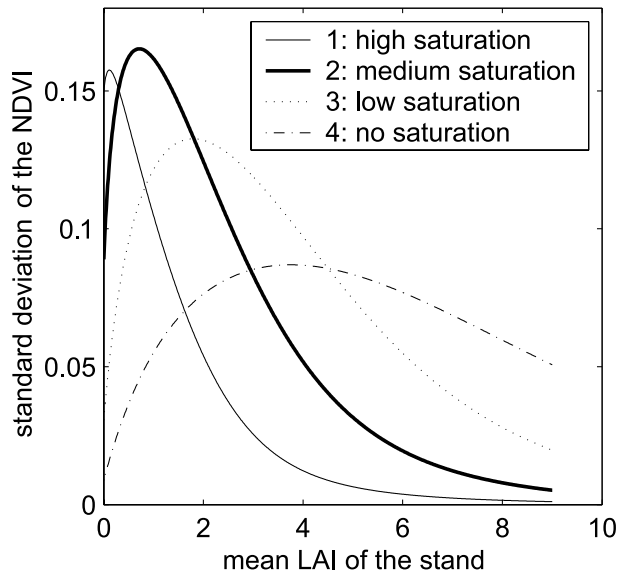

(b) With LAI Gaussian distribution

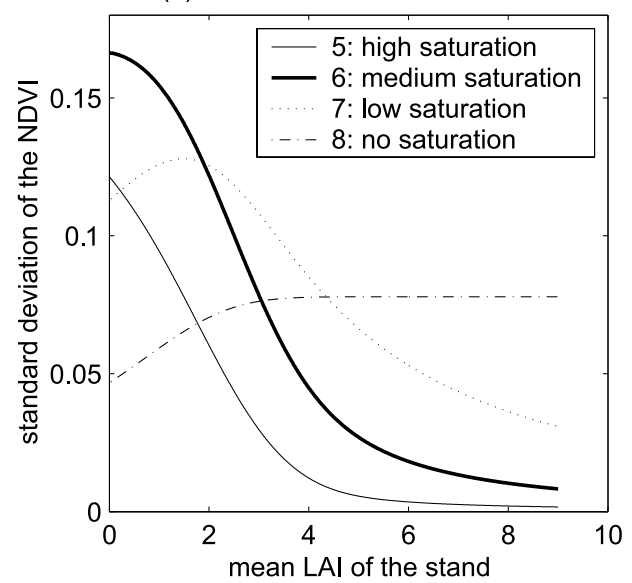

Figure 2. Model results to explain the theoretical basis of the $\overline{\mathrm{LAI}}-\sigma_{\mathrm{NDVI}}$ relationship. Two stand LAI distribution models are used: (a) the Weibull model described in Appendix A, function of the mean LAI of the stand, and (b) the Gaussian model described in the text, independent of the mean LAI of the stand. For these two distributions, four different LAI-NDVI curves are tested (Figure 1). The eight cases are numbered from 1 to 8 ; case 2 is close to the real case.

\subsection{Test of the Second Factor: Shape of the Within-Stand LAI Distribution}

[21] The distribution of the within-stand LAI is modeled by a Weibull function whose parameters (shape and scale) depend on $\overline{\mathrm{LAI}}$ (Appendix A). The nonsaturating (linear) LAI-NDVI curve shows the direct effect of the $\overline{\mathrm{LAI}}$ distribution on the $\overline{\mathrm{LAI}}-\sigma_{\mathrm{NDVI}}$ relationship: The $\sigma_{\mathrm{NDVI}}$ increases for a $\overline{\mathrm{LAI}}$ going from 0 to $4 \mathrm{~m}^{2} / \mathrm{m}^{2}$ and then, as observed above, decreases (Figure $2 \mathrm{a}$, case 4 ). On the contrary, for a Gaussian distribution and for the same linear LAI-NDVI relationship, the signal disappears: The $\sigma_{\mathrm{NDVI}}$ remains constant (Figure 2b, case 8). This shows that a part of the link between the $\sigma_{\text {NDVI }}$ and the $\overline{\mathrm{LAI}}$ comes from the distribution of the LAI within the stand. Note that the observed insensitivity of the $\sigma_{\mathrm{NDVI}}$ in the case of the Gaussian distribution does not occur for low $\overline{\mathrm{LAI}}$ since the distributions are left truncated to prevent negative LAIs. For medium saturation LAI-NDVI curve (Figure 2, cases 2 and 6), the effect of the LAI distribution is more reduced, but still important since the Weibull LAI distribution reduces the flattening of the $\overline{\mathrm{LAI}}-\sigma_{\mathrm{NDVI}}$ for high LAIs.

[22] The combination of a saturating LAI-NDVI curve and a Weibull distribution (that takes into account the real distribution of LAI) leads to a decreasing standard deviation of the NDVI for $\overline{\mathrm{LAI}}$ greater than approximately $0.5 \mathrm{~m}^{2} / \mathrm{m}^{2}$ (Figure $2 \mathrm{a}$, case 2). The logarithmic transformation of this signal leads to a linear r-square (coefficient of determination) greater than 0.9 , suggesting that the standard deviation of the NDVI follows an exponential decay with $\overline{\mathrm{LAI}}$. These results show the combined importance of the LAI distribution and the shape of the LAI-NDVI curves on the observed $\overline{\mathrm{LAI}}-\sigma_{\text {NDVI }}$ relationship, with a greater effect of the LAINDVI relationship shape.

\section{Experimental Results}

\subsection{LAI Within-Stand Variability}

[23] Since the within-stand LAI distribution partly explains the $\overline{\mathrm{LAI}}-\sigma_{\mathrm{NDVI}}$ relationship, measured $\sigma_{\mathrm{LAI}}$ varia- tions with $\overline{\mathrm{LAI}}$ (Fontainebleau forest data) are given in Figure 3 to illustrate distinctive characteristics of real LAI distribution in managed forests: $\sigma_{\text {LAI }}$ is small for low and high $\overline{\mathrm{LAI}}$, and is higher for intermediate values. This pattern shows the specific stand structure variations with $\overline{\text { LAI }}$ that are generated by the sylvicultural practices. In open and closed canopies, most measurements are performed in places with similar LAI values (low LAIs or high LAIs); this leads to low LAI standard deviation. In canopies with intermediate $\overline{\mathrm{LAI}}$, measurements are performed in more contrasting places mainly because of the discontinuous spatial distribution of trees; this leads to higher LAI standard deviation. This observed pattern is also obtained with the Weibull modeling (solid line on Figure 3), and, as developed above, mostly explains the $\overline{\mathrm{LAI}}-\sigma_{\mathrm{NDVI}}$ relationship.

\subsection{Comparison of the Methods for Predicting

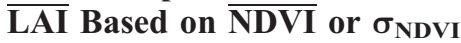

[24] Figures $4 \mathrm{a}$ and $4 \mathrm{~b}$ represent the average stand LAI (LAI) versus $\overline{\text { NDVI }}$ (Figure $4 \mathrm{a}$ ) and versus $\sigma_{\text {NDVI }}$ (Figure 4b). To fit these data, several regression models have been tested. The simple regression models that best fit the data are

$$
\begin{gathered}
\overline{L A I}=\frac{a}{\ln (\overline{N D V I})}+b \\
\overline{L A I}=a \times \ln \left(\sigma_{N D V I}\right)+b,
\end{gathered}
$$

where $\ln$ is the Napierian logarithm and $a$ and $b$ are regression parameters. The $(-1 / \ln (\mathrm{x}))$ and $(-\ln (\mathrm{x}))$ equations were applied to $\overline{\text { NDVI }}$ and $\sigma_{\text {NDVI }}$ to get linear plots that are more explanatory (Figures $4 \mathrm{c}$ and $4 \mathrm{~d}$ ); $a$ and $b$ parameters are obtained with linear regressions on these transformed data, and these regression lines are reported on the scatterplot. The r-square and root mean square errors (RMSE) of these regressions are given in Table 3. Finally, a global regression was calculated on all-year and all- 


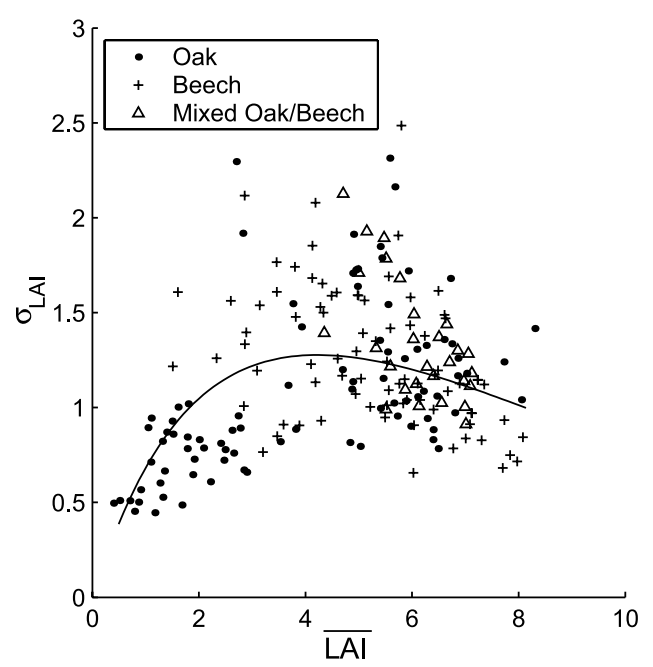

Figure 3. Standard deviation of the LAI $\left(\sigma_{\mathrm{LAI}}, \mathrm{m}^{2} / \mathrm{m}^{2}\right)$ as a function of the mean stand LAI $\left(\overline{\mathrm{LAI}}, \mathrm{m}^{2} / \mathrm{m}^{2}\right)$. Stand LAIs are obtained from ground measurements (40 to 150 PCA LAI-2000 samples per stand). Plots are presented by species. All 197 forest-stand samples between 1994 and 2004 are presented in this graph. Solid line represents the results given by the Weibull model (see Appendix A).

satellites data (Figures 4e and 4f), and the results are reported in Table 3.

[25] For a given image, results show that the two models gave nearly equal r-squares $(0.68$ for $\overline{\mathrm{NDVI}}$ and 0.71 for $\sigma_{\text {NDVI }}$ in average) and $\operatorname{RMSE}\left(0.99 \mathrm{~m}^{2} / \mathrm{m}^{2}\right.$ for $\overline{\mathrm{NDVI}}$ and $0.96 \mathrm{~m}^{2} / \mathrm{m}^{2}$ for $\sigma_{\text {NDVI }}$ in average). This means that when a single year and sensor is considered, both models are a priori equivalent. Considering the $\overline{\mathrm{LAI}}-\overline{\mathrm{NDVI}}$ relationship, the regression lines are very different from a satellite image to another in terms of slope and intercept. Soudani et al. [2006] have shown that the great difference between IKONOS NDVI and other satellites NDVI comes from the radiance spectral responses of the sensor on the red band that goes until $698 \mathrm{~nm}$ for IKONOS, whereas other sensors generally stop before $690 \mathrm{~nm}$ (see Table 2) which leads to higher $R_{R E D}$ values. Other possible differences between satellite images that causes the large NDVI scatter seen on Figures $4 \mathrm{c}$ and $4 \mathrm{e}$ may come from temporal variations in view and illumination conditions, in atmospheric effects and in biophysical and biochemical characteristics of the leaves of the forest canopy. These results show that the global $\overline{\mathrm{LAI}}-\overline{\mathrm{NDVI}}$ relationship is poor (Figure $4 \mathrm{e}, \mathrm{r}^{2}=0.35$ and $\mathrm{RMSE}=1.52 \mathrm{~m}^{2} / \mathrm{m}^{2}$ ), and that such a relationship should be calibrated for each sensor and for each year, as reported by Wang et al. [2005].

[26] This is not the case for the $\overline{\mathrm{LAI}}-\sigma_{\mathrm{NDVI}}$ relationships, whose regressions stay within a close range, whatever the sensor and the date (Figure 4d). The multiyear multisatellite regression for the prediction of the mean LAI of a stand as a function of the standard deviation of the within-stand pixels NDVI is given by (see Figure 4f)

$$
\overline{L A I}=-2.45 \times \ln \left(\sigma_{N D V I}\right)-5.58 \quad\left(259 \text { points, } \mathrm{r}^{2}=0.63\right) .
$$

The root mean square error (RMSE) of this relationship is $1.14 \mathrm{~m}^{2} / \mathrm{m}^{2}$ for all 259 forest-stand samples $(24 \%$ of the mean). The use of such a general relationship gives fairly precise results, and above all it can be used for different satellites and different years without systematically having to calibrate it with ground measurements. Nevertheless, a calibration will provide better results as may be seen in Figure $4 \mathrm{~d}$ and Table 3 . Note that all the relationships described in this section are applicable for both beech and oak stands.

\subsection{Sensitivity to Shifts of the NDVI}

[27] The stability of the $\overline{\mathrm{LAI}}-\overline{\mathrm{NDVI}}$ and $\overline{\mathrm{LAI}}-\sigma_{\mathrm{NDVI}}$ relationship to shifts on the remotely sensed NDVI images have been tested. Shifts on the NDVI may come from incorrect atmospheric correction, leaf biochemical or biophysical change during the leafy season on the same stand, or other shifts from measurement instruments (sensor drift). To test the effect of such shifts, we have modified the NDVI pixels of the entire year 1995 SPOT2 image, either adding a systematical constant (NDVI modified $=$ NDVI $-\alpha$ ) or applying a proportional bias (NDVI modified $=$ NDVI $*$ $(1-\alpha))$. The same process of NDVI extraction of the images and calculations of the mean NDVI and $\sigma_{\text {NDVI }}$ as before has been used. Both $\overline{\mathrm{LAI}}-\overline{\mathrm{NDVI}}$ and $\overline{\mathrm{LAI}}-\sigma_{\mathrm{NDVI}}$ relationships have therefore been changed and their respective stability with respect to such biases have been compared. We used a value of $\alpha=0.1$ for the calculations.

[28] Results are given in Figure 5. The $\overline{\mathrm{LAI}}-\sigma_{\mathrm{NDVI}}$ is insensitive to a constant bias whereas the $\overline{\text { LAI-NDVI }}$ appears to greatly change, experiencing a direct translation. This result is rather trivial for the constant bias, the standard deviation remaining unchanged after the addition of a constant to the variable. For a proportional bias, once again the $\overline{\mathrm{LAI}}-\sigma_{\mathrm{NDVI}}$ relationship is significantly more stable than the $\overline{\mathrm{LAI}}-\overline{\mathrm{NDVI}}$ relationship. The proportional bias, indeed, is conserved both through the average calculation and through the standard deviation calculation: $\operatorname{mean}(\beta \mathrm{X})=$ $\beta$ mean $(X)$ and $\operatorname{std}(\beta X)=\beta \operatorname{std}(X)$. The variation coefficient is of great importance in this case: The same proportional transformation on the output of a relationship (here NDVI and $\left.\sigma_{\mathrm{NDVI}}\right)$ will have very different consequences on the final relationship appearance, depending on the variation coefficient of that output. Here the $\sigma_{\text {NDVI }}$ signal shows high amplitude (variation coefficient of $77 \%$ ) compared to the low amplitude of the NDVI signal (variation coefficient of $5 \%$ ). Therefore the 0.9 factor has low consequences on the $\overline{\mathrm{LAI}}-\sigma_{\mathrm{NDVI}}$ and greater consequences on the $\overline{\mathrm{LAI}}-\overline{\mathrm{NDVI}}$ relationship (see Figure 5). The conclusions would be the same for linear transformations of the NDVI pixels.

[29] In conclusion, the $\overline{\mathrm{LAI}}-\sigma_{\mathrm{NDVI}}$ relationship is relatively insensitive to proportional or additive shifts on the image NDVI, which can partly explain its conservation between years and sensors.

\subsection{Sensitivity to the Image Spatial Resolution}

[30] The effect of the pixel size on the $\overline{\mathrm{LAI}}-\sigma_{\mathrm{NDVI}}$ relationship is tested by aggregating the IKONOS image (with an initial resolution of $4 \mathrm{~m}$ ). The pixel size is increased from $4 \mathrm{~m}$ up to $40 \mathrm{~m}$, with a 10-m step. For each new resolution, the $\sigma_{\text {NDVI }}$ of each experimental stand is calculated. Only 16 stands are used because the IKONOS 

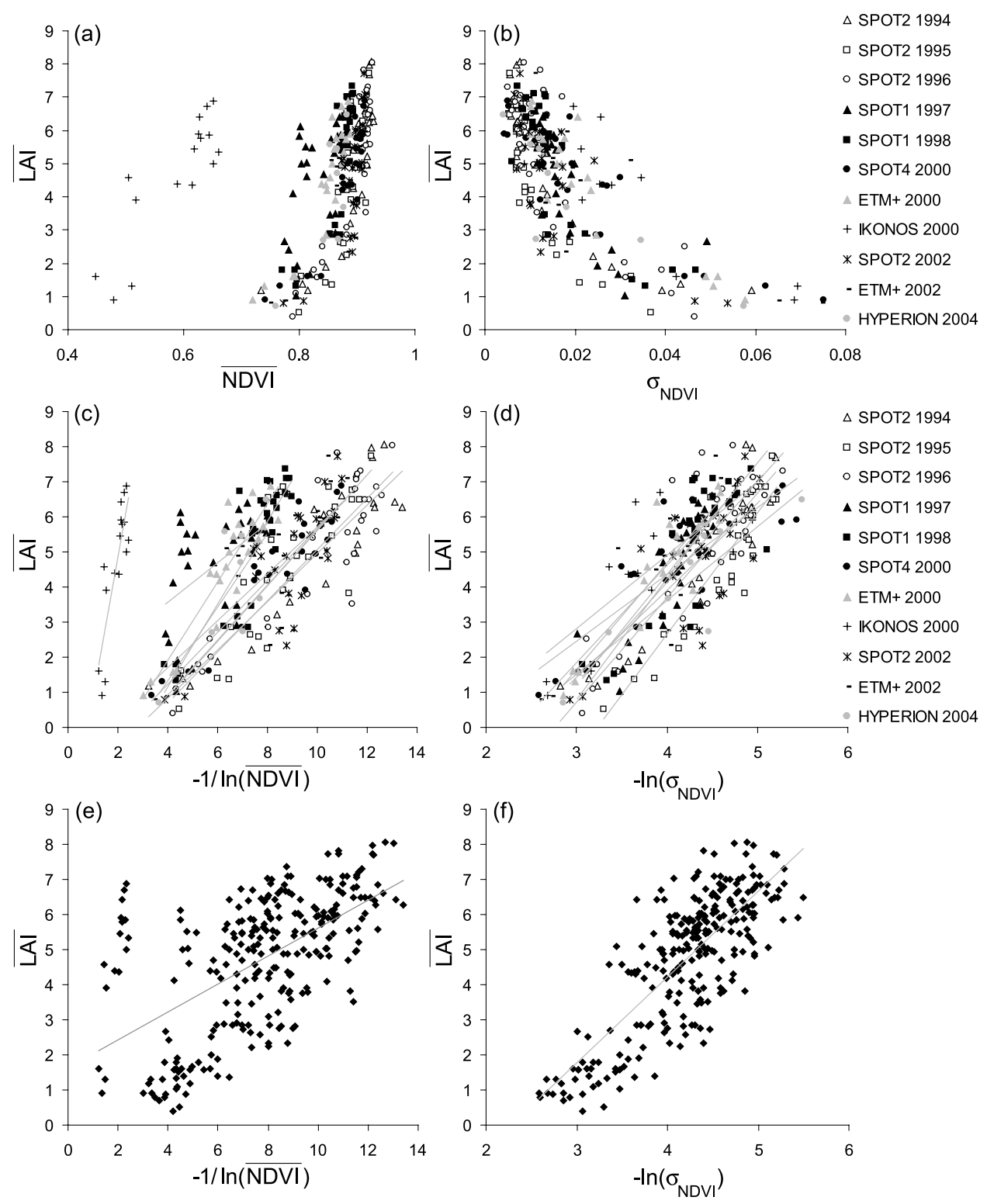

Figure 4. Comparison of (a) $\overline{\mathrm{LAI}}-\overline{\mathrm{NDVI}}$ and (b) $\overline{\mathrm{LAI}}-\sigma_{\mathrm{NDVI}}$ for 11 satellites. $\overline{\mathrm{LAI}}$ as a function of (c) $-1 / \ln (\overline{\mathrm{NDVI}})$ and $(\mathrm{d})-\ln (\overline{\mathrm{NDVI}})$ (see equations (1) and (2) in text). Gray lines are linear regressions $\left(\mathrm{r}^{2}\right.$ are given in Table 3$)$. (e, f) Same as Figures $4 \mathrm{c}$ and $4 \mathrm{~d}$ but with all 259 points together.

image does not cover the entire forest. For the 40-m resolution, two stands with fewer than 20 pixels are excluded. The r-square between $\overline{\mathrm{LAI}}$ and the $-\ln \left(\sigma_{\mathrm{NDVI}}\right)$ transformation is calculated for each resolution.

[31] A first result is that the $\overline{\mathrm{LAI}}-\sigma_{\mathrm{NDVI}}$ relationship changes because $\sigma_{\text {NDVI }}$ decreases with increasing pixel size (Figure 6). This decrease is similar to the one simulated by Gastellu-Etchegorry et al. [1999]. This is not the case for the LAI-NDVI that is insensitive to the pixel resolution.

[32] The other result (not shown) is that we cannot conclude that there are significant differences between the r-square calculated at the different resolutions, from 4 to $40 \mathrm{~m}$ (comparison of correlation coefficient test, $\alpha=0.01$ ). This means that the accuracy of the recalibrated $\overline{\mathrm{LAI}}-\sigma_{\mathrm{NDVI}}$ relationships does not change with the resolution. This result is partly due to the small number of points of the relationship. All r-square are between 0.56 and 0.69 , with an average value of 0.60 and RMSE are between 0.81 and $0.94 \mathrm{~m}^{2} / \mathrm{m}^{2}$ with an average of $0.89 \mathrm{~m}^{2} / \mathrm{m}^{2}$.

\subsection{Test of the Method Principle: Intersensor Stability of the $\sigma_{\text {NDVI }}$ Over the Whole Forest}

[33] The generality of the stability of the $\sigma_{\mathrm{NDVI}}$ between different sensors has been tested. Since we do not need LAI measurements for the inter-sensor comparison of $\overline{\mathrm{NDVI}}$ and $\sigma_{\text {NDVI }}$ only, we have used a larger number of deciduous stands in the image, instead of the previous 31 stands (provided that the images are acquired the same year during the LAI plateau (July and August), so that the LAI does not vary between the images). For that purpose, we have extracted the $\overline{\mathrm{NDVI}}$ and the $\sigma_{\mathrm{NDVI}}$ of 293 deciduous stands of the Fontainebleau forest for a given year (2000) and for 
Table 3. R-Square Coefficient and Root Mean Square Error of Linearized $\overline{\text { LAI }}-\overline{N D V I}$ and $\overline{\text { LAI }}-\sigma_{\mathrm{NDVI}}$ Relationships Plotted in Figures 4c and 4d With the Regression Model Described by Equations (1) and (2) ${ }^{\mathrm{a}}$

\begin{tabular}{|c|c|c|c|c|c|}
\hline & \multirow[b]{2}{*}{ Number of Stands } & \multicolumn{2}{|c|}{$\mathbf{r}^{2}$} & \multicolumn{2}{|c|}{ RMSE, $\mathrm{m}^{2} / \mathrm{m}^{2}$} \\
\hline & & $\overline{\mathrm{LAI}}-\overline{\mathrm{NDVI}}$ & $\overline{\mathrm{LAI}}-\sigma_{\mathrm{NDVI}}$ & $\overline{\mathrm{LAI}}-\overline{\mathrm{NDVI}}$ & $\overline{\mathrm{LAI}}-\sigma_{\mathrm{NDVI}}$ \\
\hline SPOT2 1994 & 22 & 0.84 & 0.87 & 0.86 & 0.79 \\
\hline SPOT2 1995 & 30 & 0.64 & 0.80 & 1.19 & 0.89 \\
\hline SPOT2 1996 & 31 & 0.81 & 0.69 & 0.95 & 1.19 \\
\hline SPOT1 1997 & 29 & 0.26 & 0.66 & 1.29 & 0.87 \\
\hline SPOT1 1998 & 29 & 0.79 & 0.68 & 0.87 & 1.07 \\
\hline SPOT4 2000 & 23 & 0.88 & 0.74 & 0.60 & 0.86 \\
\hline $\mathrm{ETM}+2000$ & 21 & 0.83 & 0.84 & 0.72 & 0.71 \\
\hline IKONOS 2000 & 16 & 0.72 & 0.63 & 0.96 & 1.10 \\
\hline SPOT2 2002 & 25 & 0.60 & 0.52 & 1.09 & 1.20 \\
\hline ETM+ 2002 & 25 & 0.57 & 0.63 & 1.13 & 1.05 \\
\hline HYPERION 2004 & 8 & 0.56 & 0.78 & 1.19 & 0.84 \\
\hline Average & & 0.68 & 0.71 & 0.99 & 0.96 \\
\hline All sensors together & 259 & 0.35 & 0.63 & 1.52 & 1.14 \\
\hline
\end{tabular}

aThe number of samples used in the regressions is given. The "all sensors together" line corresponds to a unique regression obtained on all the data set (Figures $4 \mathrm{e}$ and $4 \mathrm{f}$ ).

three sensors: IKONOS (with a 20-m spatial resolution), ETM+ and SPOT4. These stands were selected among the deciduous stands of the Fontainebleau forest through a visual cloud check and a surface area threshold (for stands smaller than 2 ha without the edge buffer, $\overline{\text { NDVI }}$ and $\sigma_{\mathrm{NDVI}}$ estimation are degraded due to the smaller number of pixels). $\overline{\text { NDVI }}$ and $\sigma_{\text {NDVI }}$ have then been compared stand by stand between the three satellites (Figure 7). Two statistics have been calculated: the r-square, which is a measurement of the level of correlation between the sensors, and the Fisher F-value for paired measures, which is a measure of the sensitivity of NDVI or $\sigma_{\text {NDVI }}$ to the change of sensor (the higher the F-value, the more sensitive is the variable). The F-value calculated on NDVI measured by two different sensors can be compared with the $\sigma_{\mathrm{NDVI}}$ one. The r-square and $\mathrm{F}$ values are given in Figure 7.

[34] The r-squares obtained between IKONOS $\overline{\text { NDVI }}$ and the other two sensors are poor $\left(r^{2}=0.65\right.$ with ETM + and $r^{2}=0.64$ with SPOT) because of small cirrus clouds present on the western part of the forest on the IKONOS image that increase the scattering. Without these clouds the r-square

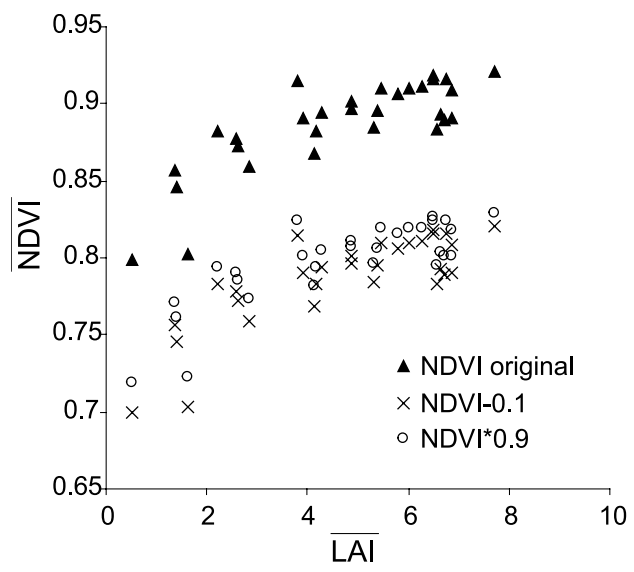

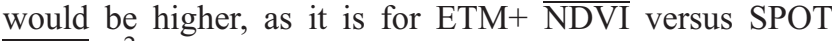
$\overline{\text { NDVI }}\left(\mathrm{r}^{2}=0.92\right)$. The between-sensors $\mathrm{r}$-squares obtained for $\sigma_{\text {NDVI }}$ are high, even when there are thin clouds $\left(\mathrm{r}^{2}=\right.$ 0.80 between IKONOS and ETM $+\sigma_{\text {NDVI }}$ and $r^{2}=0.88$ between IKONOS and SPOT $\left.\sigma_{\mathrm{NDVI}}\right)$. In the absence of clouds, between-sensors r-squares are similar for $\overline{\mathrm{NDVI}}$ and for $\sigma_{\text {NDVI }}$ (respectively $\mathrm{r}^{2}=0.92$ and $\mathrm{r}^{2}=0.91$ between ETM+ and SPOT images).

[35] The F-values are higher for intersensor NDVI than intersensor $\sigma_{\mathrm{NDVI}}$, showing that $\overline{\mathrm{NDVI}}$ is much more sensitive to a change of sensor than $\sigma_{\mathrm{NDVI}}$.

[36] These results demonstrate the stability of the $\sigma_{\mathrm{NDVI}}$ between three sensors and for the same year on a large number of stands.

\section{Discussion}

[37] The present study deals with "homogeneous" stands: they are defined as even-aged, spatially (horizontally) homogeneous in species, stand structure and tree density. Raffy et al. [2003] gave a similar definition of the stand homogeneity. In an operational manner a "homogeneous"

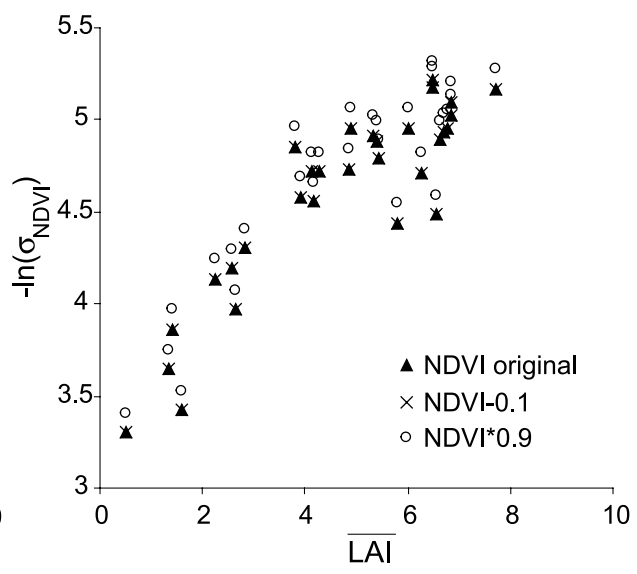

Figure 5. Test of (left) $\overline{\mathrm{LAI}}-\overline{\mathrm{NDVI}}$ and (right) $\overline{\mathrm{LAI}}-\sigma_{\mathrm{NDVI}}$ relationships sensitivity to shifts of the image pixels NDVI with a constant bias (NDVI-0.1) or a proportional bias (NDVI * 0.9). Note that original NDVI and NDVI-0.1 plots are superimposed on the $\sigma_{\text {NDVI }}$ graph. Data are from SPOT2 image for the year 1995 . 


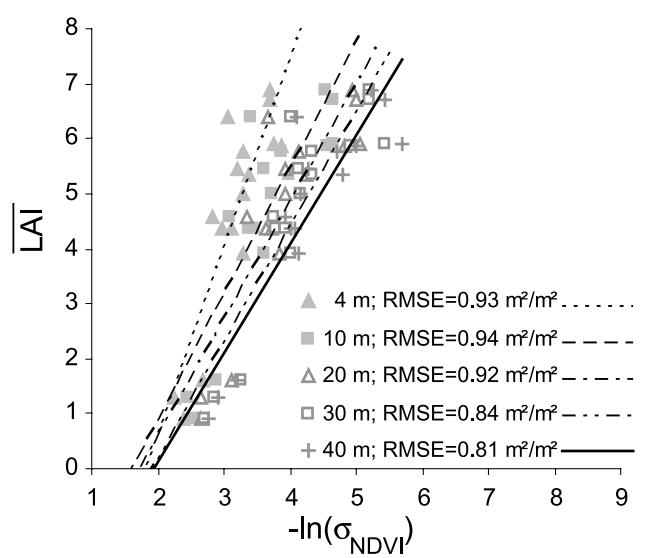

Figure 6. Change of $\overline{\mathrm{LAI}}-\sigma_{\mathrm{NDVI}}$ relationship with increasing spatial resolution (from 4 to $40 \mathrm{~m}$ ). Calculations are performed on the IKONOS image (initial resolution: $4 \mathrm{~m}$ ). stand is defined here as a stand whose LAI distribution follows the Weibull model whose parameters are given by equations (A3) and (A4) in Appendix A (see also Figure A1 in Appendix $\mathrm{A}$ for the acceptable range around the nominal relationships).

[38] The results have shown that both the local LAINDVI curve and the LAI distribution can explain the relationship between the mean LAI and the standard deviation of the NDVI of the stand. However, other unsuspected explanations may exist. The obtained relationship is modeled with strong conditions on the LAI distribution, fitted on measurements on managed forest stands that have a particular structure. For example, in this type of ecosystem, it is not possible to have high $\overline{\mathrm{LAI}}$ and high standard deviation (i.e., high heterogeneity) of the LAI in a stand (Figure 3). This fact is mainly true in managed forest. For instance a maximum variation at medium values of LAI has also been observed in Norway spruce (Picea abies (L.) Karst.) managed forest [Schlerf et al., 2005]. This should be qualified, however, for other natural ecosystems.
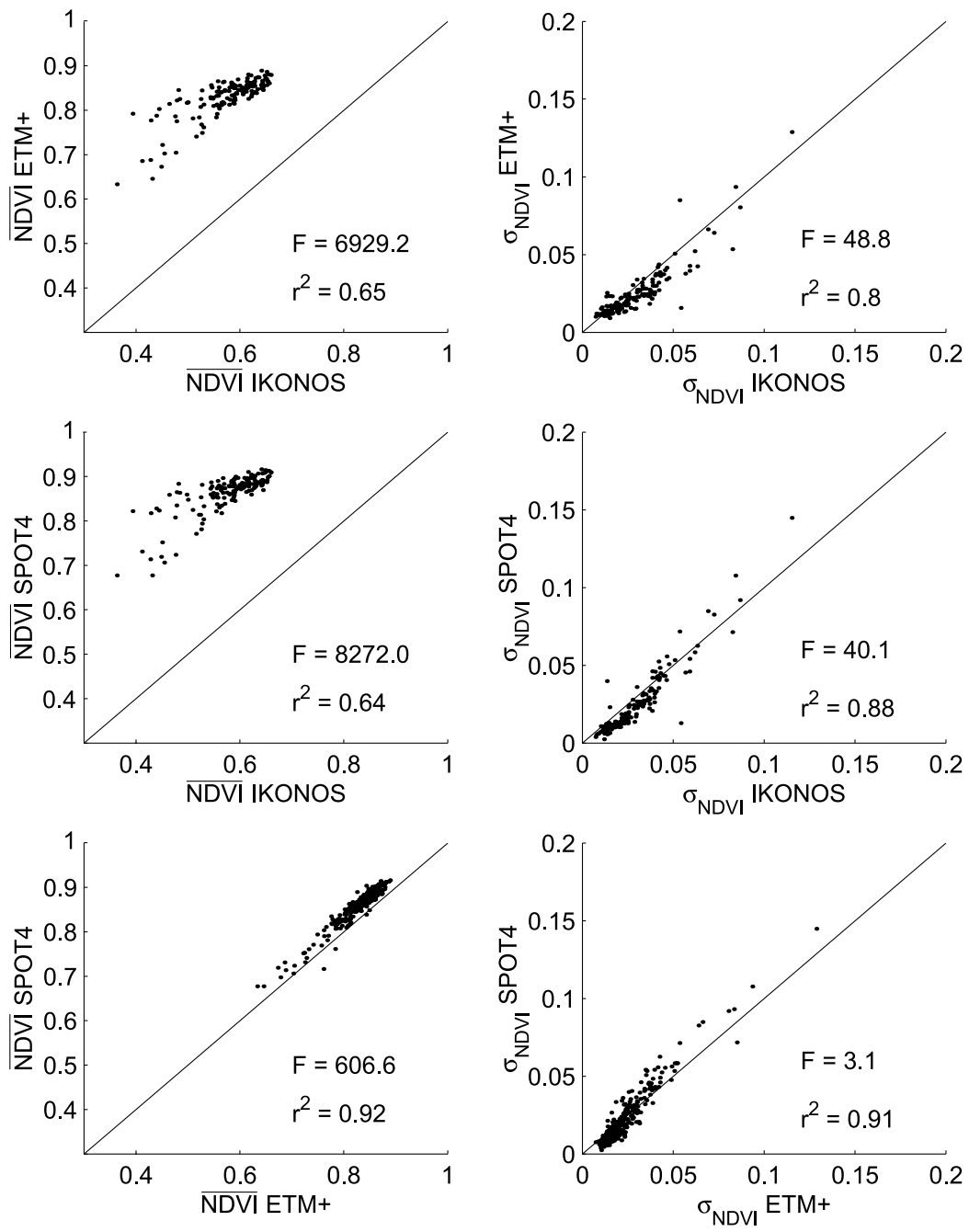

Figure 7. Between sensors stand by stand comparison of $\overline{\text { NDVI }}$ and $\sigma_{\text {NDVI }}$ in year 2000. 144 stands are plotted for the IKONOS images (top four graphs), and 293 stands (bottom two graphs). Here $\mathrm{r}^{2}$ is the coefficient of determination. $\mathrm{F}$ is the Fisher statistic for paired measures: Low F-values indicate low sensitivity of the variable ( $\overline{\mathrm{NDVI}}$ or $\left.\sigma_{\mathrm{NDVI}}\right)$ to the sensor. 
[39] The results obtained on the experimental stands and in the whole forest show that $\overline{\mathrm{LAI}}-\sigma_{\mathrm{NDVI}}$ relationship is reliable: It is very stable between satellite images in comparison with the $\overline{\mathrm{LAI}}-\overline{\mathrm{NDVI}}$ relationship. However, depending on the spatial resolution and on the stand area, the method may show some limitations related to the number of NDVI pixels in the stand: It is obvious that the number of pixels should be sufficient to get a good estimation of $\sigma_{\mathrm{NDVI}}$. Moreover, on small stands, $\sigma_{\mathrm{NDVI}}$ is more sensitive to image rectification and georeferencing errors than NDVI, especially when neighbor stands are contrasted. A large buffer width partly solves this problem. In this study, a buffer of $60 \mathrm{~m}$ (i.e., 2 pixels) was used to exclude overlapping pixels. The buffer can be reduced to one pixel width, depending on the spatial accuracy between polygons and image, and between different images if several images are used. In any case, $\sigma_{\mathrm{NDVI}}$ of stands with surface smaller than 2 ha (i.e. 22 pixels of $30 \mathrm{~m}$ ) are less stable between sensors than NDVI.

[40] Another critical consideration is the size of the NDVI pixels, i.e., integration scale of NDVI. It is obvious that the larger the pixels are, the smaller the $\sigma_{\mathrm{NDVI}}$ is, because averaging the NDVIs reduces extreme values. A consequence is that $\overline{\mathrm{LAI}}-\sigma_{\mathrm{NDVI}}$ relationship changes with the resolution. Despite this fact, we do not find any significant improvement or deterioration of these relationships in term of r-square and RMSE for resolutions ranging from $4 \mathrm{~m}$ to $40 \mathrm{~m}$. This means that $\overline{\mathrm{LAI}}$ can be obtained from $\sigma_{\mathrm{NDVI}}$ in the 4- to 40-m range, but that a specific relationship has to be used for each resolution, or resolution range (satellites with resolutions between $20 \mathrm{~m}$ and $30 \mathrm{~m}$ may be considered a single group; see Figures 4 and 6). However, the question remains open because of the limited number of stands used for these calculations (16 stands).

[41] The $\overline{\mathrm{LAI}}-\sigma_{\text {NDVI }}$ relationship given in this study (equation (3)) corresponds to sensors of 20 - or $30-\mathrm{m}$ pixel resolutions, and should only be used for satellites with these resolutions and on stands of at least 2 ha.

\section{Conclusion}

[42] As a conclusion, we list the advantages and drawbacks of the $\overline{\mathrm{LAI}}-\sigma_{\mathrm{NDVI}}$ relationship compared to the classical $\overline{\mathrm{LAI}}-\overline{\mathrm{NDVI}}$ relationship. The advantages are as follows. (1) There is a unique multiyear multisatellite relationship that gives fairly good accuracy on predicted mean stand LAI (RMSE of $1.14 \mathrm{~m}^{2} / \mathrm{m}^{2}$ ). (2) there is nearinsensitivity to proportional and additive shifts on the NDVI that may occur (satellite drifts, view and illumination conditions, atmospheric corrections, variable sensor spectral responses, leaf biochemical or biophysical change during the leafy season, etc.). (3) The relationship is apparently fairly robust (multispecies (oak and beech), multisatellite) which allows its use in various situations. The drawbacks are as follows. (1) There is a necessity to have accurate delimitations of homogeneous forest stands included into a GIS. (2) Large enough stands are necessary to have valid $\sigma_{\mathrm{NDVI}}$ estimation. In this study, a minimum threshold of 2 ha (approximately 20 pixels) is used. Because of the 60-m buffer width, the original stand surface corresponding to that threshold is around 6 ha. However, the buffer width can be reduced as discussed before, or be specific to each image.
(3) The $\overline{\mathrm{LAI}}-\sigma_{\mathrm{NDVI}}$ relationship must be recalibrated before using it on images of different resolutions. However, as far as our study goes, the accuracy of recalibrated relationships does not change much with spatial resolution: Resolutions between 4 to $40 \mathrm{~m}$ have been tested on 16 stands resulting in RMSE comprised between 0.81 and $0.94 \mathrm{~m}^{2} / \mathrm{m}^{2}$. The relationship stays nearly unchanged for resolutions between 20 and $30 \mathrm{~m}$.

[43] It must be stressed that this study was made on a particular forest and on two deciduous species (oak and beech). Preliminary results have shown that the $\overline{\mathrm{LAI}}-\sigma_{\mathrm{NDVI}}$ relationship also applies to managed coniferous stands on the Fontainebleau forest (Pinus sylvestris L.). Further work on other managed forest or other ecosystems and species is needed to test the generality of these results.

[44] The $\overline{\mathrm{LAI}}-\sigma_{\mathrm{NDVI}}$ relationship obtained in this study can be useful in biophysical models because it can be applied on remotely sensed images from different sensors and years, and therefore allows getting multiyear LAI data. Moreover, this relationship can be used without preliminary calibration, i.e., without LAI ground measurements. Finally, this method is fast and also quite simple to implement. It offers promising perspectives in applications requiring forest LAI series, especially in the climate change field and related continental biosphere studies.

\section{Appendix A: Representation of Stand LAI Distributions With Weibull Functions}

[45] Our objective is to model the distribution of the LAI within a stand as a function of the mean LAI of the stand. The suitability of the Normal, Lognormal, Logistic or twoparameter Weibull Probability Density Function (PDF) to model the LAI distribution inside a stand is investigated. We use the Anderson-Darling test, which is an improved goodness-of-fit Kolmogorov-Smirnov test [Press et al., 1996]. For a given stand it tests whether there is a difference between observed and predicted distributions, with a level $\alpha=0.05$ considered to be significant. The test is performed on each experimental stand and for each year when measurements are available (197 tests in total). Note that it is possible that two different distribution models (e.g., Logistic and Weibull) may represent well the same stand LAI distribution. The root mean square error (RMSE) of the fit of the models to the measured distribution is calculated, and an average value is given for each model.

[46] The results are given in Table A1. Results are expressed in percent of success over all stands (same method as Nanang [1998]). There are 197 tests corresponding to 31 stands that are measured at different years. We can see that the Weibull function represents the best the distribution of LAI within a stand, with about $62 \%$ of success for the Anderson-Darling test. The mean RMSE, representing the accuracy of the fit, is also lower for the Weibull than the other PDF. The two-parameter Weibull function is therefore clearly the best model for the withinstand LAI distribution.

[47] The Weibull function is widely used for fitting life data in biology and industry [Abernethy, 2000]. In forestry field, other distributions of parameters are modeled by this function. For example, the most commonly used probability density function for modeling diameter distri- 
Table A1. Results of the No-Difference Test Between Observed and Predicted Within-Stand LAI Distributions ${ }^{\mathrm{a}}$

\begin{tabular}{lcc}
\hline Distribution & A-D Test $\%$ of Success & CDF Fit Mean RMSE $\left(\times 10^{-3}\right)$ \\
\hline Normal & 47.2 & 32.0 \\
Lognormal & 37.6 & 38.0 \\
Logistic & 49.7 & 32.1 \\
Weibull & $\mathbf{6 2 . 4}$ & $\mathbf{3 0 . 1}$ \\
\hline
\end{tabular}

${ }^{\mathrm{a}}$ Test is the Anderson-Darling test, 197 samples, $\alpha=0.05$. The fit mean RMSE is given as a goodness-of-fit criterion.

butions is the Weibull function [Bailey and Dell, 1973; Nanang, 1998; Lehtonen et al., 2004]. This distribution is also used to assess the probability of strong winds in forest [Quine, 2000].

[48] The two-parameter Weibull distribution has the following PDF:

$$
f(t)=\frac{\beta}{\eta}\left(\frac{t}{\eta}\right)^{\beta-1} e^{-\left(\frac{t}{\eta}\right)^{\beta}}
$$

where $\beta$ is the shape parameter of the distribution and $\eta$ is the scale parameter ( $\beta$ and $\eta$ are positive). The Cumulative Distribution Function (CDF) of the Weibull distribution is

$$
F(t)=1-e^{-\left(\frac{t}{\eta}\right)^{\beta}} .
$$

The calculations of $\beta$ and $\eta$ for each stand were realized with Matlab (MathWorks Inc.) using the simplex search method algorithm, minimizing the square difference between the Weibull CDF and the measured LAI CDF of the stand.

[49] To get a theoretical model for the LAI distribution inside a "homogeneous" stand having only the mean LAI of the stand as driving parameter, parameters $\beta$ and $\eta$ have been plotted against the mean measured LAI of the stand. The scale parameter $\eta$ appears to be linearly correlated to the mean LAI of the stand (Figure A1). This comes from the fact that the scale parameter is close to the mean of the Weibull function,

$$
\eta=1.07 \times \overline{L A I} \quad\left(\mathrm{r}^{2}=0.99,123 \text { points }\right) .
$$

The shape parameter $\beta$ is exponentially correlated with the mean LAI (Figure A1),

$$
\beta=1.13 \times e^{0.27 \overline{L A I}} \quad\left(\mathrm{r}^{2}=0.77,123 \text { points }\right)
$$

[50] In Figure A1, all stands parameters are represented, even the ones that give a negative result in the AndersonDarling test. However, only the stands with positive results are used for the regressions (123 points over 197). It is noteworthy that when the rejected stands are included in the graph, their Weibull parameters follow the same trend that the other stands even at low mean LAI. The only difference is that the relationship is more scattered. This result suggest that even if the Weibull model was rejected with the Anderson-Darling test, equations (A3) and (A4), further included in equation (A1), are suitable for modeling the LAI distribution.

[51] A graphical representation of the modeled LAI PDF is given in Figure A2: Equation (A1) is used with the equations of $\eta$ and $\beta$ (equations (A3) and (A4)). Eight different distributions are represented: They are calculated for mean LAI going from 1 to $8 \mathrm{~m}^{2} / \mathrm{m}^{2}$. One may note that the distribution is positively skewed for low mean LAI and negatively skewed for high mean LAI.

[52] The switch from LAI distribution to NDVI distribution is achieved using a given within-stand LAI-NDVI relationship (we used here, for the graphic representation, the relationship given in Figure 2a, medium saturation case). The resulting NDVI distributions are represented in Figure A2b, according to the LAI distributions described above (mean LAI going from 1 to $8 \mathrm{~m}^{2} / \mathrm{m}^{2}$, Figure A2a). Note that the PDF are normalized to get integrals normalized to 1 , which leads to high ordinates for the narrow
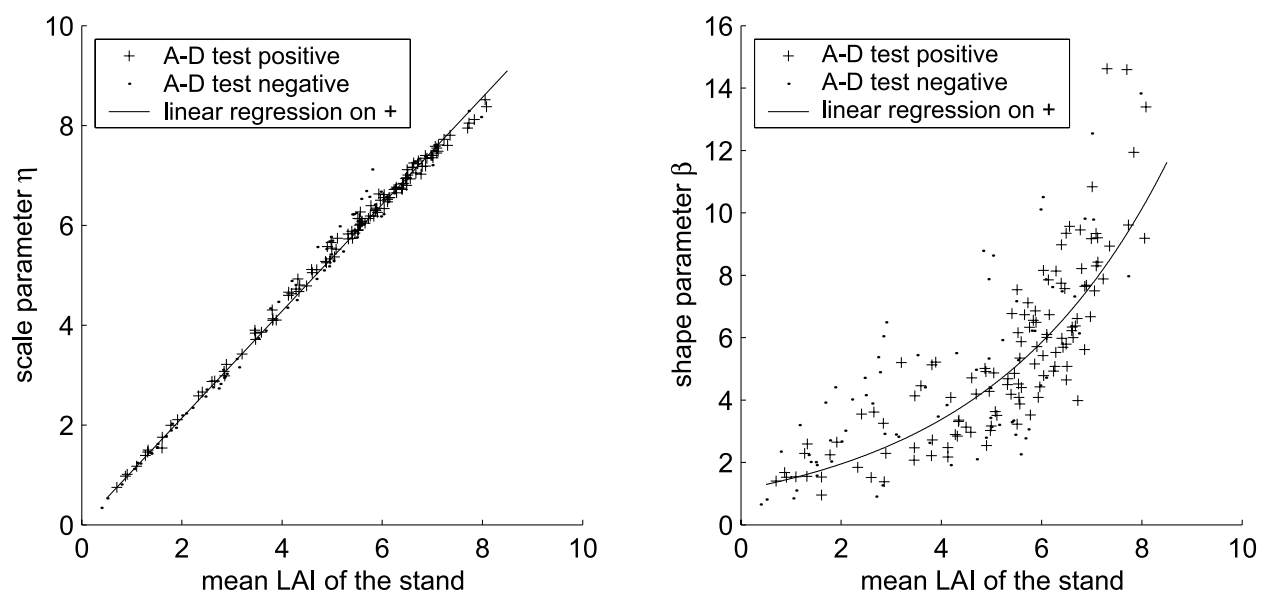

Figure A1. Representation of the scale and shape parameters ( $\eta$ and $\beta$ ) of the Weibull model (equations (A1) and (A2)) as a function of the mean LAI of the stand. These parameters are calculated for each stand as explained in the text. The regression equations are given in the text (equations (A3) and (A4)). Anderson-Darling (AD) tests are carried out on each stand, and the results of the tests are reported in the plots. 

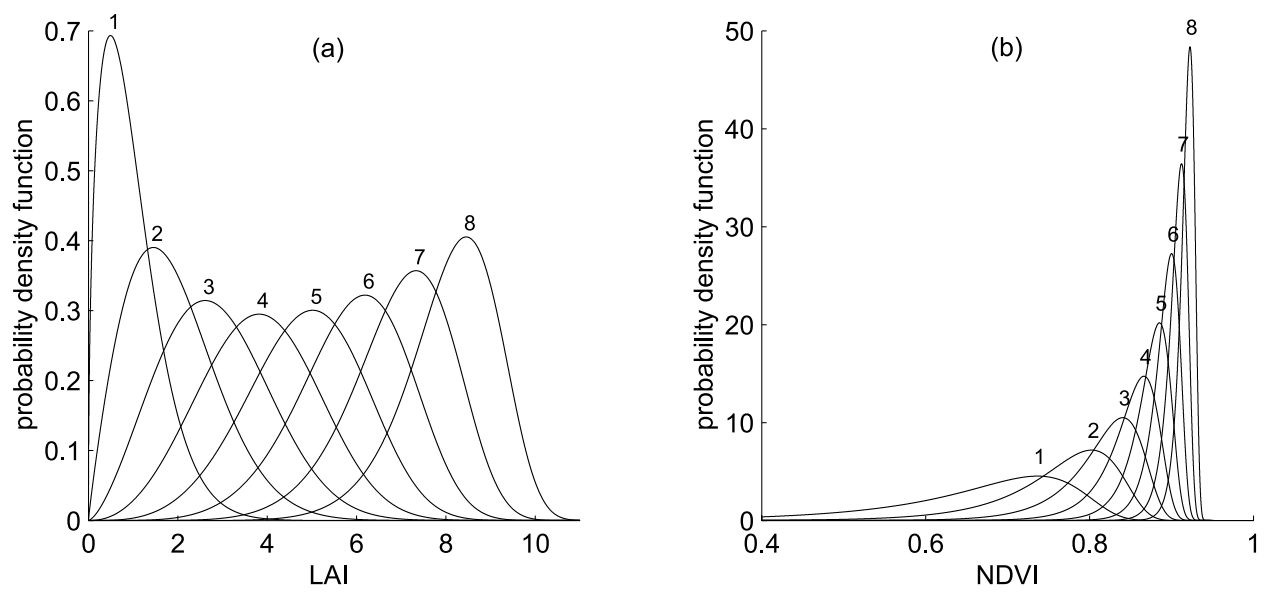

Figure A2. (a) Modeled LAI Probability Density Function. Eight different distributions are represented; they are calculated with a mean LAI going from 1 to 8 (indicated above each curve) with the equations (A3) and (A4) included in equation (A1). (b) Modeled NDVI Probability Density Function. These distributions come from the LAI distributions described in Figure A2a (LAI going from 1 to 8) and using the LAI-NDVI relationship given in Figure 3 (medium saturation).

NDVI distributions. One may observe the decrease in width of the NDVI distribution when the LAI increases. This is this feature that is studied in the present paper.

[53] Acknowledgments. We wish to thank the Office National des Forêts (ONF, the French National Office for Forestry) for giving us facilities for in situ LAI measurements and for providing us with the forest GIS database. We also thank all members of the ESE department who participated in ground data collection. The financial support from the CNRS is gratefully acknowledged. Finally, the authors would like to thank the anonymous reviewers for their constructive comments and recommendations concerning the manuscript.

\section{References}

Abernethy, R. B. (2000), The New Weibull Handbook: Reliability and Statistical Analysis for Predicting Life, Safety, Survivability, Risk, Cost and Warranty Claims, 4th ed., Barringer \& Assoc., Inc., North Palm Beach, Fla.

Anderson, M. C., C. M. U. Neale, F. Li, J. M. Norman, W. P. Kustas, H. Jayanthi, and J. Chavez (2004), Upscaling ground observations of vegetation water content, canopy height, and leaf area index during SMEX02 using aircraft and Landsat imagery, Remote Sens. Environ., 92, 447-464.

Bailey, R. L., and T. R. Dell (1973), Quantifying diameter distributions with the Weibull function, For. Sci., 19, 97-104.

Birky, A. K. (2001), NDVI and a simple model of deciduous forest seasonal dynamics, Ecol. Modell., 143(1-2), 43-58.

Chen, J. M., P. M. Rich, S. T. Gower, J. M. Norman, and S. Plummer (1997), Leaf area index of boreal forests: Theory, techniques, and measurements, J. Geophys. Res., 102(D24), 29,429-29,443.

Coburn, C. A., and A. C. B. Roberts (2004), A multiscale texture analysis procedure for improved forest stand classification, Int. J. Remote Sens., 25(20), 4287-4308

Colombo, R., D. Bellingeri, D. Fasolini, and C. M. Marino (2003), Retrieval of leaf area index in different vegetation types using high resolution satellite data, Remote Sens. Environ., 86, 120-131.

Curran, P. J. (1980), Multispectral remote sensing of vegetation amount, Prog. Phys. Geogr., 4, 315-341.

Cutini, A., G. Matteucci, and G. S. Mugnozza (1998), Estimation of leaf area index with the Li-Cor LAI 2000 in deciduous forests, For. Ecol. Manage., 105(1-3), 55-65.

Davi, H., K. Soudani, T. Deckx, E. Dufrêne, V. Le Dantec, and C. François (2006), Estimation of forest Leaf Area Index from SPOT imagery using NDVI distribution over homogeneous stands, Int. J. Remote Sens., 27(56), $885-902$.

Dufrêne, E., and N. Breda (1995), Estimation of deciduous forest leaf area index using direct and indirect methods, Oecologia, 104, 156-162.

Fassnacht, K. S., S. T. Gower, M. D. MacKenzie, E. V. Nordheim, and T. M. Lillesand (1997), Estimating the leaf area index of North Central
Wisconsin forests using the Landsat thematic mapper, Remote Sens. Environ., 61, 229-245.

Gastellu-Etchegorry, J. P., P. Guillevic, F. Zagolski, V. Demarez, V. Trichon, D. Deering, and M. Leroy (1999), Modeling BRF and radiation regime of boreal and tropical forests: I. BRF, Remote Sens. Environ., 68, 281-316.

Goel, N. S., and W. Qin (1994), Influences of canopy architecture on relationships between various vegetation indices and LAI and FPAR: A computer simulation, Remote Sens. Rev., 10(4), 309-347.

Justice, C. O., et al. (1998), The Moderate Resolution Imaging Spectroradiometer (MODIS): Land remote sensing for global change research, IEEE Trans. Geosci. Remote Sens., 36(4), 1228-1249.

Lark, R. M. (1996), Geostatistical description of texture on an aerial photograph for discriminating classes of land cover, Int. J. Remote Sens., 17(11), 2115-2133.

Le Dantec, V., E. Dufrene, and B. Saugier (2000), Interannual and spatial variation in maximum leaf area index of temperate deciduous stands, For. Ecol. Manage., 134(1-3), 71-81.

Lehtonen, A., R. Makipaa, J. Heikkinen, R. Sievanen, and J. Liski (2004), Biomass expansion factors (BEFs) for Scots pine, Norway spruce and birch according to stand age for boreal forests, For. Ecol. Manage., $188(1-3), 211-224$.

le Maire, G., H. Davi, C. François, K. Soudani, V. Le Dantec, and E. Dufrêne (2005), Modelling annual production and carbon fluxes of a large managed temperate forest using forest inventories, satellite data and field measurements, Tree Physiol., 25, 859-872.

Lillesand, T. M., and R. W. Kiefer (2000), Remote Sensing and Image Interpretation, 4th ed., John Wiley, Hoboken, N. J.

Lüdeke, M., A. Janecek, and G. H. Kohlmaier (1991), Modelling the seasonal $\mathrm{CO}_{2}$ uptake by land vegetation using the global vegetation index, Tellus, Ser. B, 43(2), $188-196$.

Miller, J. B. (1967), A formula for average foliage density, Aust. J. Bot., 15, $141-144$.

Nanang, D. M. (1998), Suitability of the normal, log-normal and Weibull distributions for fitting diameter distributions of neem plantations in northern Ghana, For. Ecol. Manage., 103(1), 1-7.

North, P. R. J. (2002), Estimation of fAPAR, LAI, and vegetation fractional cover from ATSR-2 imagery, Remote Sens. Environ., 80, 114-121.

Press, W., S. Teukolsky, W. Vetterling, and B. Flannery (1996), Numerical Recipes in Fortran 77, 2nd ed., Cambridge Univ. Press, New York.

Qi, J., Y. H. Kerr, M. S. Moran, M. Weltz, A. R. Huete, S. Sorooshian, and R. Bryant (2000), Leaf area index estimates using remotely sensed data and BRDF models in a semiarid region, Remote Sens. Environ., 73, 18 30.

Quine, C. P. (2000), Estimation of mean wind climate and probability of strong winds for wind risk assessment, Forestry, 73(3), 247-258.

Raffy, M., K. Soudani, and J. Trautmann (2003), On the variability of the LAI of homogeneous covers with respect to the surface size and application, Int. J. Remote Sens., 24(10), 2017-2035.

Rouse, J. W., R. H. Haas, J. A. Schell, and D. W. Deering (1973), Monitoring vegetation systems in the great plains with ERTS, in Third ERTS Symposium, SP-351, pp. 309-317, NASA, Washington, D. C. 


\section{LE MAIRE ET AL.: SATELLITE-INDEPENDENT LAI DETERMINATION}

Ryherd, S., and C. Woodcock (1996), Combining spectral and texture data in the segmentation of remotely sensed images, Photogramm. Eng. Remote Sens., 62(2), 181-194.

Schlerf, M., C. Atzberger, and J. Hill (2005), Remote sensing of forest biophysical variables using HyMap imaging spectrometer data, Remote Sens. Environ., 95, 177-194.

Song, C., C. E. Woodcock, K. C. Seto, M. P. Lenney, and S. A. Macomber (2001), Classification and change detection using Landsat TM data: When and how to correct atmospheric effects?, Remote Sens. Environ., $75,230-244$.

Soudani, K., C. François, G. le Maire, V. Le Dantec, and E. Dufrêne (2006), Comparative analysis of Ikonos, SPOT and ETM+ data for leaf area index estimation in temperate coniferous and deciduous forest stands, Remote Sens. Environ., 102, 161-175.

St. Onge, B. A., and F. Cavayas (1995), Estimating forest stand structure from high-resolution imagery using the directional variogram, Int. J. Remote Sens., 16(11), 1999-2021.

Teillet, P. M., K. Staenz, and D. J. Williams (1997), Effects of spectral spatial and radiometric characteristics of remote sensing vegetation indices of forested regions, Remote Sens. Environ., 61, 139-149.

Turner, D. P., W. B. Cohen, R. E. Kennedy, K. S. Fassnacht, and J. M. Briggs (1999), Relationships between leaf area index and Landsat TM spectral vegetation indices across three temperate zone sites, Remote Sens. Environ., 70, 52-68.

Walthall, C., W. Dulaney, M. Anderson, J. Norman, H. Fang, and S. Liang (2004), A comparison of empirical and neural network approaches for estimating corn and soybean leaf area index from Landsat ETM+ imagery, Remote Sens. Environ., 92, 465-474.
Wang, Q., S. Adiku, J. Tenhunen, and A. Granier (2005), On the relationship of NDVI with leaf area index in a deciduous forest site, Remote Sens. Environ., 94, 244-255.

Wicks, T. E., G. M. Smith, and P. J. Curran (2002), Polygon-based aggregation of remotely sensed data for regional ecological analyses, Int. J. Appl. Earth Obs. Geoinf., 4(2), 161-173.

Wulder, M. A. (1998), The prediction of leaf area index from forest polygons decomposed through the integration of remote sensing, GIS, UNIX, and C, Comput. Geosci., 24(2), 151-157.

Wulder, M. A., M. Lavigne, and S. Franklin (1996), High spatial resolution optical image texture for improved estimation of forest stand leaf area index, Can. J. Remote Sens., 22(4), 441-449.

Wulder, M. A., E. F. LeDrew, S. E. Franklin, and M. B. Lavigne (1998), Aerial image texture information in the estimation of northern deciduous and mixed wood forest leaf area index (LAI), Remote Sens. Environ., 64, $64-76$.

H. Davi, Unité de Recherches Forestières Méditerranéennes (UR 629), INRA, 20 avenue Antonio Vivaldi, F-84000 Avignon, France.

E. Dufrêne, C. François, B. Saugier, and K. Soudani, Laboratoire Ecologie, Systématique et Evolution (ESE), CNRS \& Université Paris Sud, Bât 362, F-91405 Orsay, France.

V. Le Dantec, Centre d'Etudes Spatiales de la Biosphère (CESBIO), 18 avenue Edouard Belin, BPI 2801, F-31400 Toulouse, France.

G. le Maire, Laboratoire des Sciences du Climat et de l'Environnement (LSCE), Unité Mixte CNRS-CEA, L'Orme des Merisiers, F-91191 Gif-surYvette, France. (guerric.le-maire@cea.fr) 